\title{
Nuevas ruralidades como reconfiguración del territorio en transformación: imaginarios sociales corregimentales a la luz de organizaciones socioculturales*
}

\author{
New ruralities as reconfiguration of the territory in transformation: \\ social imaginaries in a village in the light of sociocultural organizations
}

\author{
Natalia Andrea Salinas-Arango** \\ Mateo Sanmartín-GaViria***
}

\section{Resumen}

Objetivo. Identificar los imaginarios sociales sobre las transformaciones de lo rural a lo urbano y su incidencia en el desarrollo local desde la perspectiva de cuatro organizaciones socioculturales. Metodología. Cualitativa bajo el enfoque histórico-hermenéutico, mediante el estudio de caso, se aplicaron las técnicas de entrevista, observación y conversatorio con experto. Resultados. Se encontró que las organizaciones perciben el tránsito de un territorio con características campesinas a un corregimiento dormitorio y urbanizado, conversión dada por la explosión demográfica y la creciente y descontrolada construcción de conjuntos habitacionales en espacios antes dedicados a la agricultura, así como otras afectaciones en la vocación económica y medioambiental, lo cual conlleva a cambios socioculturales y ambientales de gran impacto para los pobladores. Conclusión. La capacidad de adaptación de las organizaciones sociales a las realidades que proponen las nuevas circunstancias en el corregimiento posibilita la búsqueda de salidas sociales y culturales para la integración social.

Palabras clave: nuevas ruralidades, imaginarios sociales, organizaciones socioculturales, San Antonio de Prado.

\footnotetext{
Abstract

Objective: To identify the social imaginaries about the transformations from the rural to the urban and their impact on local development from the perspective of four sociocultural organizations. Methodology: Qualitative research under the historical- hermeneutic approach through application of the case study, the semi-structured interview techniques, observation and expert discussion. Results: It was found that organizations perceive the transit of a territory with peasant characteristics to a

* Este artículo es resultado de la investigación "Imaginarios sociales sobre las transformaciones rural urbana y su incidencia en el desarrollo local en San Antonio de Prado”, radicada con N892B-08/17-74 en el Centro de Investigación, Desarrollo e Innovación -CIDI- de la UPB. Fue realizada por el grupo de investigación de Trabajo Social -GITS-, el semillero de investigación Dinámica Social y el grupo del Seminario de Investigación (2016) de la Facultad de Trabajo Social de la Universidad Pontificia Bolivariana.

** Universidad Pontificia Bolivariana. Medellín, Colombia. E-mail: natalia.salinas@upb.edu.co

(D) orcid.org/0000-0003-1369-514X Google Scholar

**** Universidad Pontificia Bolivariana. Medellín, Colombia. E-mail: mateo.sanmartin@upb.edu.co

(D) orcid.org/0000-0003-1762-9115 Google Scholar
} 
Nuevas ruralidades como reconfiguración del territorio en transformación: imaginarios sociales corregimentales...

dormitory and urbanized township, a conversion given by demographic explosion and the growing and uncontrolled construction of housing complexes in spaces previously dedicated to agriculture, as well as other alterations in the economic and environmental vocation, which leads to socio-cultural and environmental changes of great impact for its inhabitants. Conclusion: The ability of social organizations to adapt to the realities proposed by the new circumstances in the township, makes it possible to search for social and cultural solutions for social integration.

Key words: new ruralities, social imaginaries, sociocultural organizations, San Antonio de Prado.

\section{Introducción}

A mediados del siglo XX, la urbanización en Colombia estuvo asociada a los procesos migratorios del campo a la ciudad, producto de la industrialización, del mejoramiento de las condiciones de vida en las ciudades, así como del desplazamiento forzado, derivado de la violencia política en el campo y las dinámicas del conflicto armado. Estos factores contribuyeron en gran medida al rápido crecimiento poblacional en las periferias de las principales ciudades del país.

En el municipio de Medellín en las últimas décadas, sus corregimientos se convirtieron en una opción viable para continuar con la expansión urbana, dado el crecimiento acelerado y desordenado en la centralidad; afectando de tal manera la configuración política, cultural, social y económica corregimental y haciendo ambigua la denominación de rural en estos territorios.

En el caso del corregimiento de San Antonio de Prado (SAP) ${ }^{1}$, la declaración de zona de expansión urbanística en la década de los noventa ocasionó una transformación acelerada en la urbanización y en el incremento demográfico. En las tres últimas décadas se ha observado que SAP, antes considerado territorio rural o típicamente campesino, empieza a ser habitado por pobladores citadinos que viven en altos edificios y urbanizaciones, los cuales paulatinamente sustituyeron extensiones dedicadas al cultivo o al recreo.

Esta nueva configuración urbanística, poblacional y en el uso del suelo, también evidencia problemas en la planificación y el ordenamiento territorial, por la falta de control en los proyectos urbanísticos, la insuficiencia de equipamientos para satisfacer las necesidades de toda la población en cuanto a servicios y espacios públicos; insuficiencia de vías, señalización y aceras para el tránsito de peatones; así como en el deterioro de los recursos naturales, las fuentes hídricas que no dan abasto para suplir el consumo de las nuevas construcciones, el incremento de la contaminación ambiental y en la transformación y debilitamiento de la identidad local tradicional.

${ }^{1}$ En adelante se empleará la sigla SAP al momento de nombrar al Corregimiento de San Antonio de Prado. 
De este modo, se instala la idea de "corregimiento dormitorio" puesto que, en las prácticas cotidianas, en la mayoría de los casos, las personas salen del corregimiento muy temprano para dirigirse a sus lugares de estudio o de trabajo y llegan en la noche solo a descansar; debilitando las relaciones vecinales, la apropiación y sentido de pertenencia con el corregimiento y, en últimas, derivando en la desarticulación de las relaciones comunitarias. Con la pérdida de tradiciones históricamente fundadas en la idiosincrasia de los habitantes, se instauran nuevas prácticas sociales e identidades culturales, mixtura de valores, formas de relacionamiento, participación y maneras diversas de habitar el territorio, lo cual es interesante indagar como manera de reconocer estas reconfiguraciones.

Sin embargo, la vocación rural no se ha perdido del todo, debido a que aún se encuentra una gran parte del territorio dedicada a la actividad productiva agropecuaria, lo que lleva a reflexionar sobre la manera cómo se concibe hoy lo rural urbano. En este orden de ideas, surgen interrogantes frente a los imaginarios que se tienen frente esta transformación rural urbana, a la expansión urbanística y a la construcción de identidad local. Por ello, se indagó por las concepciones, percepciones, o bien imaginarios, de los pobladores de SAP, a partir de cuatro organizaciones socioculturales representativas en el corregimiento, frente a los cambios que se van tejiendo en los territorios que tienen la dualidad rural urbana y que configuran las llamadas nuevas ruralidades.

El estudio de los imaginarios sociales es complejo, dado que no es posible una mirada unánime o unívoca frente a un fenómeno, en estos existe una significativa carga de subjetividad desde la percepción individual, que logra colectivizarse a través de la intersubjetividad, pero que tampoco puede definirse como una generalidad inamovible.

Cornelius Castoriadis acuñó el término de imaginario social y definió el concepto: representa la concepción de figuras, formas e imágenes de aquello que los sujetos llamamos realidad. Esta realidad es construida, interpretada y leída por cada sujeto en un momento histórico determinado. Esta concepción, esta forma de interpretar el mundo, es una obra de creación constante. El sujeto va transformando la llamada realidad que lo rodea. (Erreguerena, 2004, p. 593)

Según Erreguerena (2004), Castoriadis propone la formación de las subjetividades. Mediante el imaginario social se intuye quiénes somos y qué papel se debe desempeñar en la sociedad, mediante la creación cada sujeto va transformando tanto la idea que tiene de sí como su papel y su lugar en la sociedad. Para el autor, las significaciones son imaginarias porque no corresponden a elementos racionales o reales en lo fáctico y no quedan agotadas por referencia 
Nuevas ruralidades como reconfiguración del territorio en transformación: imaginarios sociales corregimentales...

a dichos elementos, sino que están dadas por creación y son sociales porque están instituidas y son objeto de participación de un ente colectivo impersonal y anónimo.

Al tener un acercamiento a las realidades sociales que se viven en SAP y en la búsqueda de los imaginarios que se tienen sobre las trasformaciones rural-urbanas, explorar la experiencia de cuatro organizaciones sociales facilita delimitar a los actores de esa intuición que permite reconstruir la percepción de la realidad evidenciada en el imaginario social mismo.

Con dicha exploración de la intersubjetividad, desde este actor colectivo corregimental se permitió mostrar un accionar de las organizaciones mismas en medio de una realidad en movimiento, presente en la manera como han incidido en la comunidad, en las acciones encaminadas al desarrollo local, generando reflexiones en torno a lo concerniente con el desarrollo social sostenible y comunitario, las repercusiones socioculturales y ambientales que se reflejan de lo local a lo global.

De este modo, dada su importancia en el corregimiento y su actividad en el ámbito sociocultural, valga indicar aspectos generales de las organizaciones consultadas:

1) Periódico Ciudad Rural: las acciones de esta organización están encaminadas hacia la comunicación escrita y la formación de líderes como una contrapropuesta crítica y reflexiva que da voz a los ciudadanos para que expresen su sentir frente a los procesos de transformación de los fenómenos urbanísticos.

2) Parque Biblioteca José Horacio Betancur: es un espacio cultural y educativo que le permite a los ciudadanos de todas las edades acceder al conocimiento del corregimiento, especialmente en la "Sala Mi Corregimiento".

3) Corporación Casa de la Cultura SAP (CORCASAP): las principales acciones que se generan son talleres de formación, los cuales van enfocados a la cultura ciudadana, con el fin de educar a las personas $\mathrm{y}$ artistas.

4) Mesa ambiental: es una organización que gestiona soluciones frente a problemas ambientales, ya que se convierte en mediador de los ciudadanos con la administración municipal y a su vez hace veeduría de los procesos ambientales que estos encaminan. Se incluyen acciones como: eventos académicos, cabildos abiertos, foros en temas de recursos hídricos y urbanismo, de igual manera hace parte de procesos de participación ciudadana más grandes como la revisión del Plan de Ordenamiento Territorial y el Plan de Desarrollo Municipal. 
En este orden de ideas, el objetivo general que orientó esta investigación fue identificar los imaginarios sociales sobre las transformaciones rural y urbana en el corregimiento de SAP de Medellín y su incidencia en el desarrollo local, desde la perspectiva de cuatro organizaciones socioculturales locales en el periodo 2016.

Este trabajo visibiliza el potencial de la investigación social a la hora de comprender las realidades corregimentales desde la perspectiva de los ciudadanos, manifiesta en una ciudadanía activa desde sus organizaciones sociales como actores dinamizadores del desarrollo territorial local, lo cual sin duda arroja aportes para posteriores estudios sobre la temática de las nuevas ruralidades y elementos importantes a tener en cuenta en la toma de decisiones en el ámbito de lo público, de los gobiernos locales, las organizaciones comunitarias, las políticas públicas en torno al ordenamiento territorial con fundamento participativo y social.

\section{Metodología}

La investigación estuvo orientada por el método de investigación cualitativo, dado el interés por indagar por los imaginarios sociales acerca de las transformaciones del territorio desde la perspectiva de las organizaciones socioculturales de SAP, asunto que implica eminentemente las intersubjetividades de sus miembros como representantes comunitarios. En este sentido, la investigación cualitativa "aporta a la comprensión de razones, lógicas, racionalidades, modos de ser y comportarse que llenan el dato de contenido y permiten, desde los múltiples actores sociales, conocer la diversidad y heterogeneidad social" (Galeano, 2004, p. 25). El estudio de caso (Stake, 1999), como la modalidad de investigación elegida, reconoce la singularidad del fenómeno estudiado, a partir de la experiencia de los sujetos de análisis, de sus vivencias, percepciones y prácticas cotidianas. Asimismo, la investigación se abordó a partir del enfoque metodológico histórico hermenéutico (Cifuentes, 2011), mediante el cual se interpretaron las percepciones en torno a las nuevas ruralidades, mostrando de este modo la singularidad en los imaginarios tejidos en el trasegar histórico corregimental y de sus pobladores, quienes en últimas han vivenciado las transformaciones del territorio. De manera que en esta investigación, las organizaciones sociales consultadas se constituyeron en agentes ciudadanos del sentir de la población pradeña ${ }^{2}$, logrando identificar y analizar estos movimientos de cambio en los sentimientos, concepciones y subjetividades que construyen imaginarios sobre lo rural y urbano, lo que sin duda les ha permitido caminar al ritmo de las dinámicas que imponen los nuevos tiempos, logrando mostrar sus contribuciones en el mejoramiento de la calidad de vida y el desarrollo local.

\footnotetext{
${ }^{2}$ Gentilicio de los habitantes del corregimiento de San Antonio de Prado.
} 
Nuevas ruralidades como reconfiguración del territorio en transformación: imaginarios sociales corregimentales...

Se emplearon técnicas de investigación como la revisión documental, la entrevista semiestructurada, la observación y el conversatorio. El trabajo documental se centró en la indagación del material bibliográfico en torno al concepto de nuevas ruralidades e imaginarios sociales, que luego se pondría en diálogo con el material empírico; pero que igualmente aportó en la contextualización previa al trabajo de campo, mostrando la configuración corregimental en cuanto a aspectos históricos, sociales y geoespaciales.

La entrevista semiestructurada se hizo a miembros de cada una de las organizaciones sociales mapeadas, estos dieron sus aportes frente a la manera como contribuye su accionar en el desarrollo local.

Mediante la observación al territorio, con el registro en diarios de campo y mapeo, se evidenció información para la interpretación sobre los cambios y dinámicas corregimentales, así como actores sociales claves en el desarrollo local. Igualmente, se tuvo en cuenta un conversatorio con un antropólogo experto en el tema, quien hizo alusión a las transformaciones y problemáticas de SAP desde la perspectiva ambiental.

El análisis se realizó a partir de tres categorías que emergieron producto de la codificación de la información recolectada en campo: la primera dio cuenta de algunos aspectos en torno a las transformaciones rural-urbana en el corregimiento. La segunda, sobre las acciones de las cuatro organizaciones socioculturales que contribuyen al desarrollo local en un territorio en transformación. En la tercera confluye el entramado de las anteriores, mostrando a las nuevas ruralidades como un concepto que permite entender la reconfiguración del territorio en la transformación campo-ciudad.

\section{Resultados}

\section{Aspectos en torno a las transformaciones rural y urbana en el corregimiento}

En la indagación por las transformaciones rural y urbana en SAP se encontraron diversidad de percepciones y opiniones al respecto. Teniendo en cuenta que los imaginarios sociales son los que conciernen a la experiencia cotidiana y relaciona aquellos cambios que se van dando en el entorno social; en la investigación, algunos aspectos perceptuales identificados desde las organizaciones en torno a las transformaciones rural urbana indican que los pradeños han perdido su identificación con el territorio, porque al mezclarse costumbres diferentes entre campesinas y citadinas se va difuminando la línea que las dividía y muchas personas ya no distinguen si hacen parte de un territorio rural o urbano, incluso sus prácticas cotidianas pueden estar permeadas por aspectos que otrora eran típicamente campesinos o citadinos. Según Alix Vanegas, de la Corporación Casa de la Cultura San Antonio de Prado, CORCASAP: 


\begin{abstract}
Muchas personas no saben que viven en un corregimiento, muchos pobladores del corregimiento se creerían de mejor familia.Viven en un corregimiento que tiene zona rural, hay muchos habitantes que no conocen las veredas, esos serían imaginarios, muchos piensan que San Antonio es un municipio. Gente que piensa que están en un lugar muy citadino, aunque en el corregimiento se hacen mercados campesinos, los campesinos vienen y venden sus productos y hay gente que desconoce esa situación. (Alix Vanegas, Representante Legal de CORCASAP, comunicación personal, 2016)
\end{abstract}

Hace unos años, SAP era un corregimiento en el que era más evidente su ruralidad, el sustento de gran parte de la población tenía que ver con actividades económicas asociadas al campo o al comercio o bien, con una población obrera que desempeñaba sus labores por fuera del corregimiento. Sin embargo, en los últimos años ha presentado una serie de cambios en su interior, sobre todo a partir de las demandas urbanísticas y de políticas de ordenamiento territorial de Medellín o por privados con injerencia económica, como inversionistas en propiedad raíz. Teniendo en cuenta esto, las zonas rurales se han transformado, en parte, en zonas urbanas, trayendo un incremento de la población por la construcción de urbanizaciones.

Dada la expansión urbana, SAP no solo creció en densidad poblacional, sino que también la industria en el corregimiento contribuye a implementar la idea de urbanización acelerada mediante la instalación de grandes empresas, como es el caso de Porcicarnes, al adquirir prácticas más citadinas, concentrar la población y las dinámicas locales en la centralidad. Con estos cambios en la configuración del territorio, las veredas se integran al casco urbano con el nuevo transporte interbarrial, aunque algunas se están despoblando por su lejanía y la dificultad de integrarlas al proceso de transformación y de mejoramiento de las condiciones de vida de sus escasos habitantes.

No obstante, algunos de los pobladores aún se sienten identificados con el corregimiento rural, no lo ven como el territorio semiurbano que es en la actualidad. Lo cierto es que, siendo semiurbano, todavía no olvida su raíz y prácticas rurales y los pobladores tradicionales luchan por mantenerlas. Sin embargo, en su mayoría, los pradeños perciben el tránsito de un territorio con características campesinas a un corregimiento dormitorio y urbanizado, dada la creciente y descontrolada construcción de urbanizaciones, con ello la disminución de la actividad económica campesina y un evidente incremento en los problemas ambientales como la contaminación y las limitaciones en los recursos hídricos por la explosión demográfica.

Sin embargo, el cambio que más se resalta es el sociocultural, reflejado en la configuración de una identidad corregimental, hoy más difuminada, mixta, eclíptica o indefinida. Por lo tanto, las acciones desarrolladas por las organizaciones sociales, es fundamental en un territorio en 
Nuevas ruralidades como reconfiguración del territorio en transformación: imaginarios sociales corregimentales...

transformación como el de SAP, dado que contribuyen a generar procesos de concienciación de las nuevas realidades del territorio.

\section{Acciones de cuatro organizaciones comunitarias que contribuyen al desarrollo local en un territorio en transformación}

Desde hace 50 años, SAP ha sufrido una transformación tanto en aspectos demográfico como en su ordenamiento territorial, además al ser un corregimiento de Medellín se ha utilizado para la reubicación de la gran expansión urbanística de la ciudad y, en consecuencia, la construcción de nuevas urbanizaciones. Todo esto ha llevado a la gran migración hacia el corregimiento, y a su vez ha creado desarticulación entre los habitantes con raíces campesinas y los nuevos habitantes, acostumbrados a un ambiente más "citadino"; haciendo que hoy en día este fenómeno dicotómico sea claramente observado en aspectos subjetivos y objetivos, dentro del ámbito de la vida cotidiana de los habitantes de SAP.

Por consiguiente, a partir de estas transformaciones se vio la necesidad de crear organizaciones sociales encaminadas al desarrollo local y al mejoramiento de la calidad de vida de los pradeños, incluyendo a toda la población en sus planes de desarrollo local y cultural, en todos sus servicios para que aprendan y participen en las actividades propuestas, fortaleciendo a la ciudadanía activa. Crear conciencia acerca de los recursos naturales y toda su biodiversidad que el corregimiento ofrece a sus habitantes. Cada una de estas organizaciones cuenta con una metodología que contiene estrategias de acción distintas, campañas y eventos culturales que promueven la participación ciudadana.

En este contexto, en SAP se han formado organizaciones socioculturales y comunitarias que están actuando reflexivamente en el proceso de transformación rural-urbano y en el desarrollo del corregimiento. En el presente estudio se analizaron cuatro: Periódico Ciudad Rural, Mesa Ambiental, el Parque Biblioteca Horacio Betancur y Corporación Casa de la Cultura SAP (CORCASAP); ya que desde su visión y misión cuentan con proyectos de construcción social por medio de la cultura y otras estrategias, generando así que los habitantes tengan un mayor sentido de pertenencia y construcción de nuevas identidades en el corregimiento.

Según los entrevistados, SAP se caracterizó por ser un pueblo tradicional, conservador y con un arraigado sentido de pertenencia a sus creencias religiosas. Las nuevas organizaciones socioculturales contribuyen no solo a proteger la identidad cultural pradeña, sino también a dinamizar las nuevas prácticas socioculturales desde las actuales generaciones, empoderándolas para que tomen iniciativas de liderazgo, sobre todo promoviendo a los jóvenes para que logren conformar sus propios proyectos y nutran a las organizaciones mismas.

Desde su plan de trabajo, las organizaciones quieren crear un cambio en el corregimiento desarrollando propuestas encaminadas al fortalecimiento de la identidad local, tan debilitada 
con los procesos de urbanización, así como las acciones que se encaminan a favorecer el bien común de los habitantes de SAP. Sin embargo, en la indagación a algunos pobladores del corregimiento se encontró que parte del trabajo que realizan las organizaciones socioculturales es desconocida o, peor aún, no es reconocida, haciendo que sea más complicado generar participación en las acciones que realizan las mismas.

\section{Periódico Ciudad Rural}

El periódico Ciudad Rural cuenta con una política que es la defensa de los derechos humanos, promueve la no violencia y se identifica con discursos como interculturalidad, interdisciplinariedad, diversidad e inclusión. La organización tiene dos ejes que considera trasversales, uno es la comunicación y el segundo es la convivencia, trabajados desde dos componentes: el cultural y el medio ambiente.

¿La acción primordial de la organización es la comunicación comunitaria, pero a partir de ella se generan dos fortalezas que son el tema de medio ambiente y el tema de la cultura, a través de esos procesos es como se unen estos aspectos con el tema de la convivencia y la participación? (Fernando Betancur, Director del Periódico Ciudad Rural, comunicación personal, 2016)

En la entrevista, Betancur manifiesta que el crecimiento poblacional y urbanístico de SAP ha hecho que se dé una transformación en varios aspectos del corregimiento como lo económico, social, cultural, salud, educación y recreación; lo cual debe llevar a grandes retos comunicacionales para su organización.

Según el director de Ciudad Rural, una de las grandes apuestas de esta organización social es apoyar principalmente a la juventud, porque en esta siembra la semilla del progreso edificado en la diversidad y la inclusión. Esta población es a la que se busca potenciar con herramientas de aprendizaje de nuevas destrezas y canalizando a un buen fin las aptitudes artísticas y académicas de los jóvenes. A su vez, se pretende trabajar en proyectos pedagógicos que se relacionan con la convivencia y el constructo social donde la experiencia sea comunitaria y se enmarque en la tolerancia y el trabajo por las proyecciones propias y las del otro.

A los estudiantes toca enseñarles el Plan de Ordenamiento Territorial, más de su territorio, la gente de acá sabe más de Europa que de su mismo territorio. Se quiere trabajar mucho con la juventud para que los chicos protejan su territorio. Se promueven movimientos de mujeres, se defiende la inclusión, la integralidad de la participación, se muestra la importancia 
Nuevas ruralidades como reconfiguración del territorio en transformación: imaginarios sociales corregimentales...

de verse entre niños, jóvenes y adultos. (Fernando Betancur, Director del Periódico Ciudad Rural, comunicación personal, 2016)

De esta manera, el Periódico Ciudad Rural es una organización social que permite la comunicación en el corregimiento y facilita a sus habitantes estar informados de lo que sucede en lo local. La comunicación es importante también para contribuir con el desarrollo por medio de programas, artículos, proyectos, entre otros medios de concienciación de la propia realidad. Con ello se gestan procesos intergeneracionales que promueven la integración, el desarrollo y una perspectiva de ciudadanía activa que aporta al bien común.

\section{Parque Biblioteca José Horacio Betancur}

El Parque Biblioteca hace parte del sistema de bibliotecas de Medellín que tienen como finalidad generar espacios acogedores, que fomenten el encuentro ciudadano, la formación y el disfrute de las expresiones culturales por medio de la palabra, la lúdica, la investigación y la estética. Para ello, brindan diferentes servicios desde lo educativo y cultural a los ciudadanos pradeños, con el fin de conectar lo urbano y lo rural, dando a conocer también las dinámicas del corregimiento (Parque Biblioteca José Horacio Betancur, 2016).

Se encuentra ubicado justo en un lugar en el que se hace evidente la combinación entre lo urbano y lo rural, casi como símbolo de ese diálogo entre estas dos realidades, ya que el edificio del Parque Biblioteca es una bella obra arquitectónica, rodeada de galpones de pollos y terrenos para el cultivo de hortalizas y viviendas tradicionales del pueblo, en contraste con grandes edificios, urbanizaciones en construcción y de una carretera principal que conecta al corregimiento con el centro de Medellín y otros municipios del área metropolitana como Itagüí y La Estrella.

Como organización social es una fuerza viva local que dinamiza y hace parte de los escenarios que dan visión macro al corregimiento como es el Consejo de Cultura, la Mesa de Trabajo del Parque Biblioteca, la Mesa Ambiental, la Mesa de la Infancia y Adolescencia. También participa en procesos como las actualizaciones de desarrollo local, planes de desarrollo cultural. (Janeth Gallego, Directora del Parque Biblioteca José Horacio Betancur, comunicación personal, 2016)

Es un espacio público hecho para la comunidad, donde se brinda una gran variedad de servicios para todos los ciudadanos de SAP, siendo la participación ciudadana activa una muestra de la apropiación de este por parte de sus habitantes y de algunas instituciones del corregimiento, 
haciendo que no solo sea un equipamiento municipal más, sino que se constituya en un importante escenario que contribuye al fortalecimiento de un pensamiento cultural, social y político dentro del corregimiento, aportando al desarrollo individual y colectivo pero, ante todo, generando reflexión sobre el territorio y sus transformaciones.

\section{Mesa ambiental}

La Mesa ambiental se impulsó en 2003, a raíz de evitar las consecuencias ambientales negativas luego de la instalación del relleno sanitario llamado "El Guacal”, ubicado en el límite entre Heliconia y SAP. Se necesitó de una organización de la comunidad vigilante de ese proceso, entonces se reunió un grupo de líderes que configuró esta nueva corporación en SAP.

Esta organización busca tramitar todos los requerimientos ambientales del corregimiento, siendo una de sus principales funciones la de velar por la armonía ambiental, buscando soluciones a las posibles amenazas ambientales que se puedan producir en el corregimiento. En este sentido, la mesa ambiental es un interlocutor de la ciudadanía con la administración municipal y corregimental, es un organismo de veeduría ciudadana. Gefrey Valencia dice que,
A medida en que se van dando todos estos cambios del campo a la ciudad, el medio ambiente y su biodiversidad se está viendo perjudicado, no solo por la contaminación que dejan las construcciones sino también porque entre más se construya menos áreas campestres quedan para el desarrollo de la vida y del sustento de las personas que aún habitan el corregimiento. Para el control de los efectos que deja este proceso de construcción de urbanizaciones sobre el medio ambiente, se creó una organización llamada Mesa Ambiental de San Antonio de Prado, que es una forma organizativa local, autogestionaria y de libre participación ciudadana en la ruralidad del municipio. (Gefrey Valencia Moreno, Asociado a la Mesa Ambiental de SAP, comunicación personal, 2016)

La Mesa ambiental se enfoca en la educación y gestión socio ambiental local con visión regional, integrando el reconocimiento participativo de problemáticas y potencialidades territoriales, la corporación planea, gestiona y realiza acciones con enfoque medio ambiental. Aliada con las organizaciones de base (juntas de acción comunal, acueductos comunitarios, ONG, instituciones educativas, PRAES), representantes de instituciones públicas y personas naturales no afiliadas a organizaciones. 
Nuevas ruralidades como reconfiguración del territorio en transformación: imaginarios sociales corregimentales...

\title{
Corporación Casa de la Cultura-CORCASAP
}

A partir del diálogo con una de sus líderes, Alix Vanegas, se conoce que CORCASAP es una entidad privada con peso en el imaginario colectivo por ser reconocida como la casa de la cultura del corregimiento; por tal motivo recibe recursos del Estado para desarrollar las actividades culturales, pero está configurada como entidad sin ánimo de lucro, cuya función es brindar programas de formación artística y cultural a la comunidad. Dicta clases en áreas artísticas: danza, teatro, música, artes plásticas, artesanías, origami y expresión corporal.

\begin{abstract}
Algunos talleres tienen un costo ya que es de algún modo una forma de subsistir como organización y también se desarrollan programas con la Alcaldía de Medellín a través de convenios y licitaciones públicas; se brinda también programación cultural, es decir, eventos desde la música, la danza y el teatro [...]. (Alix Vanegas, Representante Legal de CORCASAP, comunicación personal, 2016)
\end{abstract}

Según Alix Vanegas, las acciones de CORCASAP se focalizan sobre todo en la población joven, ya que estos han tenido el imaginario de ser excluidos de muchos procesos y proyectos llevadas a cabo dentro del corregimiento. Así, CORCASAP en asociación con la unidad de vida articulada - UVA — ha generado nuevas oportunidades y espacios de esparcimiento para los jóvenes como el deporte al aire libre, gimnasios y clases de expresión corporal (Alix Vanegas, Representante Legal de CORCASAP, comunicación personal, 2016).

Al ser muy importante el impulso a las artes, su misión trasciende cuando también busca contribuir al desarrollo cultural en SAP, contando con varios enfoques en diferentes temas como el patrimonio cultural local, la oferta en acciones culturales y educativas, en la planeación cultural del territorio y la inclusión de las identidades culturales, coexistiendo la diversidad en un territorio en transformación.

\section{Discusión}

\section{Nuevas ruralidades: un concepto para entender la reconfiguración del territorio en la transformación campo ciudad}

El concepto nuevas ruralidades contiene varias acepciones, según las indagaciones realizadas por Kay (2007), quien se preguntaba por su significado, dejando en claro que su génesis es ambigua e indeterminada. 
En la búsqueda de un esclarecimiento conceptual, De Grammont (2008) denomina las nuevas ruralidades a los cambios que han tenido lugar en las últimas décadas en la organización y en las funciones de los espacios rurales tradicionales, o como se ha dicho, en los espacios no urbanos. Entre estos cambios se genera la ruptura de los límites entre lo urbano y lo rural, "lo tradicional y lo moderno, la agricultura y la industria, así como el replantear del sentido de las relaciones y complementariedades entre estos ámbitos, superando el carácter residual o “atrasado" que tradicionalmente se le asigna a lo rural” (Grajales y Concheiro, 2009, p. 146).

Ruiz y Delgado (2008) refieren que el término “nuevas ruralidades” se utiliza para representar las nuevas formas de organización y el cambio en las funciones de los espacios tradicionalmente "no urbanos", los cuales han tenido un aumento en la movilidad de personas, bienes y mensajes, deslocalización de actividades económicas, nuevos usos especializados (maquilas, segunda residencia, sitios turísticos, parques y zonas de desarrollo), surgimiento de nuevas redes sociales, así como diversificación de usos (residenciales, de esparcimiento y productivas), que los espacios rurales ejercen de manera creciente.

La existencia del fenómeno ha sido intensamente estudiada y se ha asociado a los términos de urbanismo rural, nueva ruralidad o rururbanización, generando relaciones entre las actividades, usos y formas de vida urbanas y rurales, cuyo resultado se plasma en una nueva concepción del espacio y de los actores sociales que interactúan en este (Egio y Torrejón, 2014).

De esta concepción nace un discurso donde lo urbano ya no está únicamente en las ciudades, sino también en zonas que fueron típicamente campesinas. Los conceptos tradicionales de lo rural y lo urbano pasan a tener una reconfiguración en la que,

La tierra, cultivable o no cultivable, ha dejado de tener esa única función de producir alimentos, o en general materias primas. Nuevos factores económicos han entrado en juego, de forma que el agricultor no es sino un agente más en competencia por el uso y control de ese suelo, aunque siga siendo el que más superficie domina y administra (y esta sería quizás una de las principales diferencias entre estos territorios con los puramente metropolitanos e incluso urbanos). (Baigorri, 1995, p. 151)

Por ello surge fuertemente la perspectiva del desarrollo local, entendido como una acción ejercida por parte de los actores sociales del territorio inmediato, con el propósito de empoderar a los ciudadanos y optimizar los recursos de su espacio y comunidad, con miras a generar bienestar y calidad de vida. Desde esta perspectiva, es la población la que gestiona el desarrollo desde su trabajo integrador y colectivo, reconociendo sus necesidades y potencialidades para resolver sus problemas, sosteniendo el protagonismo en los procesos de desarrollo (Carvajal, 2012). 
Nuevas ruralidades como reconfiguración del territorio en transformación: imaginarios sociales corregimentales...

En este sentido, entender la nueva configuración territorial, desde concepciones como las nuevas ruralidades, y así, los imaginarios sociales, es claves para así identificar todas aquellas creencias y percepciones de los habitantes sobre las transformaciones en su territorio y el desarrollo. En el caso de SAP se destaca que los imaginarios de los pobladores, en este caso representados en las organizaciones socioculturales consultadas, están orientados hacia la idea de que entre más se encuentre el corregimiento conectado al casco urbano, se presenta una configuración territorial más cercana a las características de lo típicamente urbano y, por tanto, el corregimiento está "más desarrollado", abandonando paulatinamente su vocación rural, perdiendo de esta forma la identificación que tradicionalmente contaban los corregimientos en Medellín como zonas campesinas o rurales.

Además, otras poblaciones como desplazados, afros y personas citadinas caracterizan el territorio como semiurbano. Sin embargo, a raíz de tan acelerada expansión de SAP, los habitantes han perdido una identificación específica y unívoca con el territorio, ya que se presenta una mezcla de costumbres, formas de ser y estar diferentes que hace que muchas personas ya no distingan si hacen parte de un territorio rural o urbano.

Frente a la inmensa crisis del sector rural y la creciente necesidad de diseñar nuevas capacidades en su construcción, surge el enfoque de la nueva ruralidad. Esta propuesta plantea una comprensión de la ruralidad que supere la visión productivista y el dualismo rural urbano, con el fin de captar las múltiples dimensiones del desarrollo humano, fundamentadas en el enfoque territorial, en un desarrollo institucional coherente y en la defensa de la cultura. (Vergara, 2011, p. 33)

En este sentido, es muy válido el esfuerzo de las organizaciones sociales que aportan al desarrollo social y cultural, en el que se intenta superar cierta añoranza conservadora de los pobladores tradicionales de un territorio netamente campesino, a revisar nuevas formas de ser y estar, replanteando concepciones erradas del desarrollo, en las que se incluyen nuevos sentidos del territorio, siendo críticos frente a los problemas y los retos de la acelerada urbanización. También estas organizaciones favorecen con sus acciones el ser más incluyentes y dinamizadores de la participación, procurando con sus estrategias propiciar una ciudadanía activa que contribuye colectivamente a la generación de iniciativas de desarrollo integral e integrador. 


\section{Conclusiones}

Existe una reconfiguración del territorio que otrora se denominó típicamente campesino o rural, a la idea de la contrastación, amalgamamiento o articulación entre lo rural y urbano en lo local, dando como resultado lo que algunos autores denominan nuevas ruralidades. Esta reconfiguración territorial no se da solo desde las prácticas productivas y el cambio en el uso del suelo, sino sobre todo en los imaginarios de sus habitantes y las prácticas sociales y culturales sobre las que conciben su localidad y se apropian del territorio mismo.

Frente a los problemas ambientales y socioculturales, suscitados por la proliferación de las construcciones de viviendas urbanizadas, la disminución en la producción agropecuaria, la empleabilidad baja en el campo, la idea de corregimiento dormitorio; hay grandes retos frente al desarrollo local, desde una mirada sostenible y sustentable con el ambiente, hasta la tarea de dinamizarla participación social y comunitaria, que posibilite los procesos organizativos de las comunidades y fortalezca el sentido su pertenencia con el territorio.

El desarrollo no se limita a las transformaciones materiales del espacio y de la vivienda, sobre todo tiene que ver con el mejoramiento integral de la calidad de vida en el territorio desde los aspectos sociales, ambientales, económicos y culturales. La construcción acelerada de urbanizaciones en el corregimiento de SAP no es un garante de desarrollo. Esto se ratifica a partir de las organizaciones socioculturales consultadas, que tienen como percepción que esta ola de urbanización no trae consigo mayores beneficios para el territorio ni para la población que habita el mismo.

Se destaca que, pese a los cambios socioculturales y ambientales de gran impacto para sus pobladores, las organizaciones sociales tienen una significativa capacidad de adaptación a las nuevas circunstancias, que posibilita la búsqueda de salidas concertadas socialmente para la integración de la identidad local en busca del bien común. La mayoría de habitantes del corregimiento, tienen una idea positiva frente a las cuatro organizaciones socioculturales que han implementado acciones que contribuyen al desarrollo local, aunque no siempre es una generalidad el reconocimiento de sus actuaciones.

Las organizaciones apuestan a la intervención, a partir de estrategias de acción que contribuyen a forjar nuevas prácticas medioambientales de protección, a promoverlos valores, las tradiciones y costumbres locales, a favorecer la educación y el fortalecimiento comunitario. Mucho se debe hacer para gestar desde la ciudadanía, unas prácticas democratizantes en defensa de la localidad, encaminando el desarrollo a lo social y cultural y no solo a la dimensión de lo económico, en el que promueva el bienestar de todos. 
Nuevas ruralidades como reconfiguración del territorio en transformación: imaginarios sociales corregimentales...

\section{Referencias}

Baigorri, A. (1995). De lo rural a lo urbano. Hipótesis sobre las dificultades de mantener la separación epistemológica entre Sociología Rural y Sociología Urbana en el marco del actual proceso de urbanización global. Recuperado de http://www.eweb.unex.es/eweb/sociolog/ BAIGORRI/papers/rurbano.pdf.

Carvajal, A. (2012). ¿Modelos alternativos de desarrollo o modelos alternativos al desarrollo? Recuperado de http://www.bibliotecavirtual.info/wp-content/uploads/2012/03/ Modelos-alternativos-del-desarrollo-Carvajal-Arizaldo.pdf.

Cifuentes, R. (2011). Diseño de proyecto de investigación cualitativa. Buenos Aires, Argentina: Noveduc.

De Grammont, H. (2008). El concepto de nueva ruralidad. En E. Pérez., M. A. Farah. y H. De Grammont. (Comps.), La nueva ruralidad en América Latina. Avances teóricos y evidencias empíricas (pp. 23 -44). Bogotá, Colombia: Pontificia Universidad Javeriana.

Egio, C. y Torrejón, E. (2014). Actores sociales y ordenamiento territorial rural: los corregimientos de Medellín, Colombia. Bitácora, 13, 2(24), 31-41. Recuperado de https: / / dialnet.unirioja.es/servlet/articulo?codigo $=5001895$.

Erreguerena, J. (2004). El imaginario social en la modernidad. Revista Anuario de investigación, 2003, 592-606.

Galeano, E. (2004). Diseño de proyectos en la investigación cualitativa, Medellín, Colombia: Fondo Editorial Universidad Eafit.

Grajales, S. y Concheiro, L. (2009). Nueva ruralidad y desarrollo territorial: Una perspectiva desde los sujetos sociales. Veredas: Revista del Pensamiento Sociológico, (18), 145-167.

Kay, C. (2007). Algunas reflexiones sobre los estudios rurales en América Latina.

Iconos. Revista de Ciencias Sociales, (29), 31-50.

Otzen, T. y Manterola, C. (2017). Técnicas de muestreo sobre una población a

Estudio. Int. J. Morphol. Recuperado de https://scielo.conicyt.cl/pdf/ijmorphol/v35n1/ art37.pdf.

Ruiz, N. y Delgado, J. (2008). Territorio y nuevas ruralidades: un recorrido teórico sobre las transformaciones de la relación campo-ciudad. Santiago, Chile: Eure.

Stake, R. (1999). Investigación con estudio de casos, Madrid, España: Morata.

Vergara,W. (2011). Desarrollo del subdesarrollo o nueva ruralidad para Colombia: Cartografías del desarrollo rural. Revista de la Universidad de La Salle, (55), 33-66. 